\title{
Laboratory diagnostic tools for checking Ebola viral infections in Africa
}

\author{
Polycarp Chia ${ }^{1}$, Elvis Fon Tatah $^{2}$, Kenneth Yongabi ${ }^{3}$ \\ ${ }^{1}$ Department of Biochemistry, Catholic University of Cameroon, Bamenda, Cameroon \\ ${ }^{2}$ Science for Life Foundation, Bamenda, Cameroon \\ ${ }^{3}$ Phyto-Biotechnology Research Foundation Institute, Catholic University of Cameroon, Bamenda, Cameroon
}

Email address:

polycarpc@gmail.com (Polycarp C.)

\section{To cite this article:}

Polycarp Chia, Elvis Fon Tatah, Kenneth Yongabi. Laboratory Diagnostic Tools for Checking Ebola Viral Infections in Africa. American Journal of Clinical and Experimental Medicine. Special Issue: Clinical Innovations, Developments in the Diagnosis, Management and Prevention of Ebola Disease (Marburg fever) and Hemorrhagic Fevers. Vol. 3, No. 1-1, 2015, pp. 29-32.

doi: $10.11648 /$ j.ajcem.s.2015030101.16

\begin{abstract}
EBOV share many symptoms with a lot of common diseases, so only a well trained Laboratorian can properly collect samples, handle, do differential diagnosis and contain the disease. Quality assurance and control should be on-going in medical Laboratyories. BSL-4 laboratories should be built in African countries where this disease is prevalent. The government should develop a maintenance culture for the infrastructure. Maximum containment is needed when working with this virus as $90 \%$ of infected people die.
\end{abstract}

Keywords: Symptoms, Laboratories, Differential Diagnosis, Quality Assurance, BSL-4 Laboratory, Maintenance Culture, Maximum Containment

\section{Introduction}

In health care, each disease has an underlying cause and many effects (the signs and symptoms).i.e. diseases share signs and symptoms. Therefore, clinicians can only conjecture as their diagnosis are always subjective about the cause of disease but the definitive diagnosis is objective and is done in the laboratory. If a case of EVD is suspected after clinical assessment the following testing should be performed urgently as it is important that other more common and potentially fatal diseases including malaria, typhoid fever, shigellosis, cholera, leptospirosis, plague, rickettsiosis, relapsing fever, meningitis, hepatitis, bacteraemia and other viral haemorrhagic fevers are considered in the differential diagnosis of patients presenting with suspected EVD. Diagnosing Ebola HF in an individual who has been infected for only a few days is difficult, because the early symptoms, such as red eyes and a skin rash, are nonspecific to ebolavirus infection and are seen often in patients with more commonly occurring diseases. As many as $90 \%$ of patients die from the EVD disease. Patients usually die from low blood pressure (shock) rather than from blood loss. Specimens such as blood must be sent to BSL-4 laboratories, which are located in developed countries, from an outbreak area, which is often very remote. The shipment of specimens for virus isolation under favorable conditions (cold chain during the period from shipment to arrival) is often difficult.

CAPACITY BUILDING is very necessary in Africa: There is an urgent need Africans laboratory scientist to be trained to diagnose, trace and treat Ebola in their own countries in Africa for rapid response to epidemics to be effective.

Sample collection: prior to any sample collection it is paramount to ensure that any specimens for testing are transported appropriately and testing is performed safely. Since our local hospitals do not handle EVD disease routinely laboratory directors and microbiologists must also be contacted prior to the collection of any specimens so that preparations can be made to receive the specimen. The following should be observed in the collection of all patient specimens suspected of EVD:

- Only specimens essential for diagnosis or monitoring should be obtained.

- Specimens should be obtained by staff experienced in the required techniques.

- Glass specimen collection devices/containers should not be used, unless there is no other alternatives 
The same protective clothing(personal protective equipment-PEE) as described for other hospital staff should be worn by those obtaining laboratory specimens with the addition of double gloving to facilitate the decontamination of the exterior of the specimen container.

These include:

- Fluid-resistant, long-sleeved cuffed gown

- Double gloves

- Full face shield

- Surgical or procedure mask

The need for additional personal protective equipment (PPE) such as foot/leg coverings, head coverings, the use of fit tested N95 or a similar mask or specific biohazard suits depends on the potential for fluid contact or aerosolization as determined by the procedure being performed and the presence of clinical symptoms that increase the likelihood of contact with body fluids. It should be noted that these instances will be rare and the PPE recommended above is sufficient to protect the health care provider from infection.

Labels used on specimen containers should be able to withstand cleaning with disinfectant, specimen tubes should be labeled before collection to reduce specimen handling mixed up. Labels must bear the patient's name, hospital identification code, source of the specimen, date of collection, and the nature of the suspected infection.

Cleaning the exterior of the specimen container within the patient room is important.

Once the specimen is collected, the entire outside surface of each specimen container should be wiped with a hospitalgrade disinfectant, and then the outer layer of gloves can be removed.

Clinical laboratory specimens should each be placed into a separate sealable plastic biohazard bags, and then sealed, and the outer surface should be decontaminated with hospitalgrade disinfectant.

A fully completed laboratory requisition form for each sample should be placed in a separate pocket of the biohazard bag, not inside the sealed compartment with the sample.

Specimens should then be placed in a durable, leak-proof secondary container ideally held in the antechamber of the patient room, or if not possible, outside of the patient room. Once sealed, the secondary container must be delivered directly to the specimen handling area of the laboratory and should not be left unattended while awaiting transportation.

Automated delivery (pneumatic tube) systems should not be used as they may disseminate aerosols in the event of a spill or breakage.

Laboratory staff should be alerted to the nature of the specimens, which once received should remain in the custody of designated persons from the sample receipt until testing is complete.

Aliquotting of specimens collected for EVD should be avoided if at all possible.

Each sample for EVD-specific testing must be submitted with its own separate requisition form requesting Ebola virus testing.

NB Other tests requested on same requisition should be cancelled.

If additional tests are requested, separate samples must be submitted, each with its own laboratory requisition, clearly stating patient's suspected diagnosis and risk factors. Other tests may be delayed pending Ebola virus testing results.

\section{Specimen Handling/Processing in the Laboratory}

Any laboratory staff and/or cleaner involved in handling, manipulating, processing, or testing of non-inactivated clinical specimens, including malaria smears, should do so in a class II biological safety cabinet with enhanced precautions, including:

Fluid-resistant, long-sleeved cuffed gown

Gloves: note double gloves may be used when manipulating uncontained specimens in the class II biosafety cabinet (BSC). Once the procedure in the BSC is complete, the outer gloves (which may have been contaminated) are removed and discarded inside the BSC and the inner gloves are removed and discarded outside the BSC.

Full face shield

Fit-tested N95 or other approved particulate respirator

The need for additional PPE such as the use of foot/leg coverings, head coverings or specific biohazard suits depends on the potential for fluid contact as determined by the procedure being performed and the presence of clinical symptoms that increase the likelihood of contact with body fluids. It should be noted that these instances will be rare and the PPE recommended above is sufficient to protect the health care provider from infection.

The use of N95 or other approved particulate respirator is recommended for laboratory testing due to the possibility of aerosol generating procedures in the opening, processing and testing in the laboratory setting, despite the lack of evidence of transmission in this manner.

\subsection{Pre-Treatment}

All pretreatment and manipulation should occur within a class II biological safety cabinet with enhanced precautions for laboratory testing described above.

Pretreatment of specimens reduces the titer of Ebola virus and may facilitate the measurement of substances in nonclosed systems. As recommended by the CDC, pretreatment of serum can be achieved with the combination of "heatinactivation at $56^{\circ} \mathrm{C}$ and polyethylene glycol p-tertoctylphenyl ether (Triton( $\left.\left({ }^{\circledR}\right) \mathrm{X}-100\right) *$; treatment with $10 \mu \mathrm{L}$ of $10 \%$ Triton(®) X-100 per $1 \mathrm{~mL}$ of serum for 1 hour reduces the titer of hemorrhagic fever viruses in serum, although $100 \%$ efficacy in inactivating these viruses should not be assumed." Later in the same document states: "Heat inactivation alone may be of some benefit in reducing infectivity.".If using heat pre-treatment alone, heating for one hour at $60^{\circ} \mathrm{C}$ is recommended (Pre-treatment is also achieved by lysis procedures used for nucleic acid extraction e.g. guanidinium thiocyanate 
Blood smears (for malaria, thin blood films) are not infectious for EVD viruses after standard fixation in methanol.

\subsection{Use of Analyzers for Testing}

Non-inactivated specimens can be processed in automated analysers for hematologic and biochemical testing that are closed and do not require removal of the top of the blood collection tube, provided there is proper disposal of waste fluids and the machine can be decontaminated after use.

If closed systems for hematology and chemistry testing are not available, you must discuss testing with the core laboratory director before any specimen collection. If approved, all specimens handling from the accessioning window through to the running on the machine must be done wearing full PPE (as described above) and any manipulation of the specimen, including the removal of the cap, must be done in the BSL II cabinet.

Routine cleaning and disinfecting procedures after use can be used for automated analyzers as recommended by the manufacturer.

All waste including specimen tubes, cuvettes and other liquid or solid waste must be disposed safely as bio hazardous waste.

Any good result from the laboratory is as good as the sample collected so the right sample must be collected appropriately by certified competent Laboratorians who should follow the SOPs strictly as they are source of danger to others and the environment if the sample is not properly stored.

In outbreaks of EHF, infections are confirmed by various laboratory diagnostic methods. These include virus isolation, reverse transcription-PCR (RT-PCR), including real-time quantitative RT-PCR, antigen-capture enzyme- linked immunosorbent assay (ELISA), antigen detection by immune-staining, and IgG- and IgM-ELISA using authentic virus antigens.

Table 1. Timing Use in the Diagnosis After Symptoms Manifestation

\begin{tabular}{lll}
\hline SN & Timeline of Infection & Diagnostic tests available \\
\hline & & Antigen-capture enzyme-linked immunosorbent assay (ELISA) testing IgM ELISA \\
1 & Within a few days after symptoms begin & $\begin{array}{l}\text { Polymerase chain reaction (PCR) } \\
\text { Virus isolation (viral culture in Vero cells) }\end{array}$ \\
2 & Later in disease course or after recovery & $\begin{array}{l}\text { IgM and IgG antibodies } \\
\text { Immunohistochemistry testing }\end{array}$ \\
3 & $\begin{array}{l}\text { Retrospectively in deceased } \\
\text { patients(serum and tissues) }\end{array}$ & $\begin{array}{l}\text { (b) PCR } \\
\text { (c) Virus isolation }\end{array}$ \\
\hline
\end{tabular}

Ebola Virus 2014 West Africa Outbreak - CDC website link

NB. In early stages of the disease symptoms only IgM antibodies be seen plasma in acute stage.

- Polymerase Chain Reaction (PCR) - a DNA test to match the DNA (RNA) from the sample to known Ebola DNA

- IgG are usually seen in chronic infections (after recovery)

- Retrospective testing after death, virus can be isolated from serum or tissues can be used to identify the presence of the virus

\section{Conclusion}

Diagnostics for Ebola virus (EVD) must be sensitive, specific, and reliable because misdiagnosis would bring huge turmoil to society. Therefore, the diagnosis of Ebola virus fevers (EVF) must not rely on any single diagnostic method alone. The risk of misdiagnosis must be extremely minimized In Ebola haemorrahgic fever (EHF) outbreak areas, patients with EVF must be isolated. This indicates that a falsepositive result will put an individual at unnecessary risk of infection by making the person be placed in a high-risk environment such as an isolation ward. A false-negative result will allow persons who are infected with EDV to be released into the community with the understanding that they do not have viral hemorrhagic fever, when in fact they have the potential to become highly contagious and cause person- to-person transmission of these viruses in the community. The information that a Medical Laboratory Scientist gives to the doctor absolutely influences the medical treatment a patient will receive.

\section{Recommendation}

In under-sourced health systems of Africa which always struggles during epidemics as their facilities are overwhelmed, robust-research findings are urgently needed to contain and respond to further outbreaks. Due to the virulence of this Zaire Ebola virus it must be contain so that it cannot fall into the hands of terrorist with their dare-devil exploits on humanity. Surveillance and notification with the laboratory being a major component of the team is primordial. The virus should be inactivated and used in mice to raise antibodies as treatment for infected people.

Virus isolation: Virus isolation is a basic, simple, and sensitive method for diagnosis of EHF. EDV grow well in a large variety of cell lines, but Vero cells (derived from the kidney of an African green monkey) and Vero E6 cells are commonly used. Specimens such as blood must be sent to BSL-4 laboratories, which are located in developed countries, from an outbreak area, which is often very remote. The shipment of specimens for virus isolation under favorable conditions (cold chain during the period from shipment to arrival) is often difficult. Therefore, diagnostic criteria based 
on virus isolation alone will not yield an etiologic diagnosis in time.

Current methods for inactivating filoviruses are limited to high doses of irradiation or formalin treatment, which may cause structural perturbations that are reflected by poor immunogenicity. Kelly et al (2007) reported a novel inactivation technique for Zaire Ebola virus (ZEBOV) that uses the photoinduced alkylating probe 1,5iodonaphthylazide (INA).

INA is incorporated into lipid bilayers and, when activated by ultraviolet irradiation, alkylates the proteins therein. INA treatment of ZEBOV resulted in the complete loss of infectivity in cells. Results of electron microscopy and viruscapture assays suggested the preservation of conformational surface epitopes. Challenge with 50,000 pfu of INAinactivated, mouse-adapted ZEBOV did not cause disease or death in mice. A single vaccination with INA-inactivated ZEBOV (equivalent to 5_104 pfu) protected mice against lethal challenge with $100 \overline{0}$ pfu of ZEBOV. INA-inactivated virus induced a protective response in $100 \%$ of mice when administered 3 days before challenge. Thus, INA may have significant potential for the development of vaccines and immunotherapeutics for filoviruses and other enveloped viruses

Strengthen laboratory services with on-going trainings. BSL-4 laboratory should be in all countries especially in Africa. Rapid response teams for epidemics.

Granting of a professional council for medical laboratory scientist of Cameroon with a directorate in the Ministry of Public Health. This would enable those doing laboratory medicine to classify medical laboratories (BSL-1, BSL-2, BSL-3 and BSL-4) and monitor them as well quality control and/or assurance will be guaranteed. Most of our doctors know it all as the they do not use the laboratory services in their health units as an act of commission not omission. A survey needs to be done to see the health units that do not use laboratory services at all either because the laboratories are not there or the clinicians deliberately refuse to use them and treat their patients' base on signs and symptoms.

Biosketch

Manager of Laboratory Services, Phytobiotechnology Research Foundation (PRF) Bamenda Cameroon.

Full member of Cameroon Association of Medical Laboratory Sciences. Membership card number 164 of 1306-2003

Member of the Association of Professions of Nurses, Midwives and Health Technician of Cameroon. Membership number 4236 of 24-06-2002.

\section{References}

[1] Australian Public Health Laboratory Network: Laboratory Precautions for Samples Collected from Patients with Suspected Viral Haemorrhagic Fevers

[2] CDC: http://www.cdc.gov/vhf/ebola/hcp/interim-guidancespecimen-collection-submission-patients-suspected-infection- ebola.html

[3] CDC: Interim Guidance for Managing Patients with Suspected Viral Haemorrhagic Fever in U.S. Hospitals

[4] Ebola Virus 2014 West Africa Outbreak - CDC website link

[5] Borio, L., T. Inglesby, C. J. Peters, A. L. Schmaljohn, J. M. Hughes, P. B. Jahrling, T. Ksiazek, K. M. Johnson, A. Meyerhoff, T. O'Toole, M. S. Ascher, J. Bartlett, J. G. Breman, E. M. Eitzen, Jr., M. Hamburg, J. Hauer, D. A. Henderson, R. T. Johnson, G. Kwik, M. Layton, S. Lillibridge, G. J. Nabel, M. T. Osterholm, T. M. Perl, P. Russell, and K. Tonat. (2002). Hemorrhagic fever viruses as biological weapons: medical and public health management. JAMA 287:2391-2405

[6] Drosten, C., S. Gottig, S. Schilling, M. Asper, M. Panning, H. Schmitz, and S. Gunther. (2002). Rapid detection and quantification of RNA of Ebola and Marburg viruses, Lassa virus, Crimean-Congo hemorrhagic fever virus, Rift Valley fever virus, dengue virus, and yellow fever virus by real-time reverse transcription-PCR. J. Clin. Microbiol. 40:2323-2330

[7] Feldmann, H., S. Jones, H. D. Klenk, and H. J. Schnittler. (2003). Ebola virus: from discovery to vaccine. Nat. Rev. Immunol. 3:677-685

[8] Ikegami, T., M. Niikura, M. Saijo, M. E. Miranda, A. B. Calaor, M. Hernandez, L. P. Acosta, D. L. Manalo, I. Kurane, Y. Yoshikawa, and S. Morikawa. (2003). Antigen capture enzyme-linked immunosorbent assay for specific detection of Reston Ebola virus nucleoprotein. Clin. Diagn. Lab. Immunol. $10: 552-557$

[9] Leroy, E. M., S. Baize, C. Y. Lu, J. B. McCormick, A. J. Georges, M. C. Georges-Courbot, J. Lansoud-Soukate, and S. P. Fisher-Hoch. (2000). Diagnosis of Ebola haemorrhagic fever by RT-PCR in an epidemic setting. J. Med. Virol. 60:463-467.

[10] Lucht, A., R. Grunow, P. Moller, H. Feldmann, and S. Becker. (2003). Development, characterization and use of monoclonal VP40-antibodies for the detection of Ebola virus. J. Virol. Methods 111:21-28.

[11] Mitchell SW and McCormick JB, .J Clin. Microbiol. 1984, 20(3):486.)

[12] Niedrig, M., H. Schmitz, S. Becker, S. Gunther, J. ter Meulen, H. Meyer, H. Ellerbrok, A. Nitsche, H. R. Gelderblom, and C. Drosten. (2004). First international quality assurance study on the rapid detection of viral agents of bioterrorism. J. Clin. Microbiol. 42:1753-1755.

[13] Niikura, M., T. Ikegami, M. Saijo, I. Kurane, M. E. Miranda, and S. Morikawa. (2001). Detection of Ebola viral antigen by enzyme-linked immunosorbent assay using a novel monoclonal antibody to nucleoprotein. J. Clin. Microbiol. 39:3267-3271.

[14] Mitchell S.W and McCormick J.B (1984), .J Clin. Microbiol. 1984, 20(3):486.)

[15] Towner, J. S., P. E. Rollin, D. G. Bausch, A. Sanchez, S. M. Crary, M. Vincent, W. F. Lee, C. F. Spiropoulou, T. G. Ksiazek, M. Lukwiya, F. Kaducu, R. Downing, and S. T. Nichol. (2004). Rapid diagnosis of Ebola hemorrhagic fever by reverse transcription-PCR in an outbreak setting and assessment of patient viral load as a predictor of outcome. J. Virol. 78:4330-4341.

[16] www.cdc.gov/HAI/pdfs/bbp/VHFinterimGuidance05_19_05.p df, accessed August 11, 2014) 